\title{
Anticonsumo basado en preocupaciones sociales y medioambientales: un análisis del país de origen y la industria
}

\author{
Nieves García de Frutos \\ José Manuel Ortega Egea \\ Javier Martínez del Río \\ Universidad de Almería
}

\section{Resumen}

Este trabajo explora los antecedentes de la evitación de un producto basada en las percepciones sociales y medioambientales ligadas a la industria y al país de origen, para hacer un amplio análisis sobre las causas del rechazo de los productos de un país. Para esto, se adopta un enfoque cualitativointerpretativo consistente en 21 entrevistas llevadas a cabo en España. Las entrevistas se centraron tanto en cuestiones generales que genera un país, ligadas a percepciones político-económicas, sociales y medioambientales, como en cuestiones ligadas específicamente a la industria (sector textil) y además muestran cómo estas percepciones se relacionan con la resistencia a consumir o el anticonsumo. Los resultados muestran que los consumidores españoles sienten cierto rechazo hacia los productos procedentes de países extranjeros - siendo China el ejemplo más frecuente-, ligado a las percepciones sociales y medioambientales que suscitan dichos países.

Palabras clave: anticonsumo, país de origen, imagen medioambiental, imagen social, sector textil.

Códigos JEL: F18 y M16.

\begin{abstract}
This work delves into the country based antecedents of product avoidance by exploring the consumers' general economic, social and environmental concerns associated to a given country and industry. To accomplish these purposes, a qualitative, interpretive approach is adopted: 21 in-depth interviews were carried out in Spain. The interviews focused both on country based and product specific (apparel) economic, social and environmental concerns. The findings broadly show that social and environmental concerns drive animosity feelings toward foreign products among Spanish consumers -being China the most frequent target country of animosity.
\end{abstract}

Key words: product avoidance, country of origin, environmental image, social image, apparel.

JEL classification: F18 y M16.

\section{Introducción}

El anticonsumo - al igual que las acciones de consumo - comprende una gran variedad de prácticas que afectan a distintos objetivos potenciales (Iyer y Muncy, 2009). Aunque la literatura ha identificado distintos motivos subyacentes a estos comportamientos como, por ejemplo, la falta de identificación del individuo con los valores de la empresa o malas experiencias pasadas (Lee, Motion y Conroy, 2009), 
resultan de especial interés aquellos comportamientos de anticonsumo que persiguen una mejora de las condiciones sociales y medioambientales. Este auge del anticonsumo social o 'verde' presenta una creciente importancia en muchas partes del mundo, y se ve fomentado por la actual situación de crisis económica y por el auge de Internet y las redes sociales.

La literatura sobre anticonsumo señala que ciertos consumidores rechazarán la compra de productos si consideran que éstos, o las condiciones en que se producen, son perjudiciales para el medio ambiente o implican algún tipo de explotación de los trabajadores (Lee et al., 2009). El presente trabajo propone el análisis de éstos fenómenos desde el punto de vista del país de origen del producto como objeto de anticonsumo. Aunque no ha sido tratado explícitamente desde el punto de vista del anticonsumo, hay evidencia suficiente para concebir el país de origen de un producto como objeto de rechazo por parte del consumidor (véase, por ejemplo, Nijssen y Douglas, 2004). A este respecto, la literatura sobre 'país de origen' sugiere que las imágenes y reacciones del consumidor hacia otros países (positivas o negativas) son contingentes a la industria analizada (Roth y Diamantopoulos, 2009). Esto sugiere la idoneidad del estudio del país de origen como objeto de anticonsumo desde dos perspectivas relacionadas: por una parte, desde la perspectiva del país 'en general' y, por otra, desde la perspectiva de la 'industria', en relación con ese país de origen.

Así, el presente trabajo explora los principales antecedentes - vinculados al país de origen - de la evitación/rechazo de productos extranjeros, profundizando en los fenómenos de resistencia al consumo y anticonsumo, ligados a cuestiones sociales y medioambientales en la industria textil china. Lograr una comprensión más profunda de los antecedentes del anticonsumo basado en cuestiones sociales y medioambientales tiene una importancia crítica porque dicha comprensión ayuda a que investigadores, administraciones públicas y empresas puedan identificar y predecir qué cuestiones sociales y medioambientales afectan a la aceptación de los productos de una industria en el extranjero y, consecuentemente, al rendimiento de dicha industria. Por ejemplo, en la industria textil de China, la explotación de los trabajadores o el abuso de sustancias contaminantes en los tintes de la ropa por parte de algunas empresas 'free-rider' pueden afectar las percepciones de los consumidores sobre la calidad de los productos de todo el país. Por ello, como señalan Jennings y Zandbergen (1995, p. 1022), «es el conjunto de todas las organizaciones lo que debe ser sostenible». El estudio del anticonsumo hace evidente que el comportamiento social y medioambiental de algunas empresas o instituciones de una industria puede tener implicaciones económicas, sociales y ecológicas para el resto de las empresas del país en su conjunto.

Sin embargo, al tratarse de un fenómeno complejo y relativamente poco analizado, se empleará una perspectiva exploratoria, en la que se tratarán de descubrir en primer lugar cuáles son los principales motivos que llevan a la evitación de productos procedentes de un determinado país de origen, para luego explorar el papel que las cuestiones sociales y medioambientales juegan en el conjunto de éstos. De forma más general, se explorará la variedad de razones que subyacen a los sentimientos de 
animosidad o antipatía hacia países extranjeros. Para conseguir estos objetivos, se adopta un enfoque cualitativo e interpretativo. Los resultados obtenidos proporcionan información de interés para el estudio del impacto del comportamiento social y medioambiental de las empresas sobre la evitación o rechazo del consumo referido a una industria/país, con repercusiones institucionales, así como implicaciones relevantes para el marketing internacional.

\section{Antecedentes teóricos}

Los movimientos de anticonsumo están ganando poder y visibilidad, sobre todo en las sociedades industrializadas. Chatzidakis y Lee (2012, p. 191) definen el anticonsumo como aquellos «fenómenos que van contra la adquisición, uso y desecho de ciertos bienes». Así, el 'anticonsumo' se expresa de manera subjetiva a través de una gran cantidad de manifestaciones (Cherrier, Black y Lee, 2011). Pueden diferenciarse distintas manifestaciones del anticonsumo por el alcance del comportamiento y por los objetivos que pretenden conseguir (Iyer y Muncy, 2009). En cuanto al alcance del anticonsumo, éste puede variar desde un tipo de producto - por ejemplo, el consumo de alcohol (Piacentini y Bannister, 2009) - o marca en concreto - por ejemplo, rechazo a la cadena de cafeterías Starbucks (Thompson y Arsel, 2004)—, hasta la reducción, evitación o rechazo del consumo en términos generales -comportamiento característico de los 'simplificadores voluntarios' (Huneke, 2005). Con respecto a los objetivos perseguidos por el anticonsumo, la literatura diferencia también dos grandes grupos: auto-creación e impacto social. Ya en la introducción se apuntaba la importancia que el anticonsumo puede tener a la hora de definir y expresar los valores e imagen del individuo. Por tanto, en primer lugar, la evitación de ciertos productos/marcas concretos puede deberse al deseo del consumidor de no verse asociado con los valores que ese producto/marca transmite (Hogg et al., 2009); un rechazo al consumo de forma general puede suponer un intento de vida alejado de los valores consumistas y el paradigma dominante (Cherrier, 2009). En segundo lugar, el rechazo de ciertos productos/marcas puede estar motivado por su impacto en la sociedad. Este impacto puede centrarse en algún aspecto concreto de la sociedad, como la mejora del medio ambiente (Black y Cherrier, 2010), o puede buscar cambios más generalizados en el paradigma occidental (Iyer y Muncy, 2009).

Los aspectos morales que conllevan las decisiones de consumo son un importante antecedente a tener en cuenta a la hora de analizar el anticonsumo. En particular, la reciente publicación de números especiales dedicados a 'sostenibilidad' y 'anticonsumo' - en prestigiosas revistas de gestión y marketing, como son Journal of Business Research (2009), International Journal of Consumer Studies (2009), Journal of Consumer Behavior (2010) o Journal of Macromarketing (2010) - ejemplifica la importancia e interés de investigar formas alternativas como un medio para lograr una mayor sostenibilidad ambiental. El consumo sostenible es un término amplio que se refiere a las distintas formas de reducir la huella ecológica del consumo (Black y 
Cherrier, 2010). Hay evidencia de dos estrategias (básicas) de consumo dirigidas a la sostenibilidad ambiental. La versión más 'relajada o flexible' del consumo sostenible gira en torno a la compra de productos 'verdes' y la reducción (a un cierto nivel) de los niveles actuales de consumo; por tanto, no implica una alteración excesiva de los hábitos compra de los consumidores (Moisander, 2007). Por el contrario, el consumidor verde más 'radical' tenderá a rechazar el consumo y comportamientos medioambientalmente no sostenibles, a partir de un replanteamiento mucho más profundo de su estilo de vida (Black y Cherrier, 2010; Moisander, 2007). Parece lógico esperar que - siguiendo una estrategia 'flexible' o 'radical' - ciertos consumidores eviten o rechacen aquellos productos que consideren perjudiciales el medio ambiente.

La literatura sobre marketing internacional ha demostrado que el país de origen de un producto es un atributo importante en la evaluación y elección de productos por parte de los consumidores (Balabanis y Diamantopoulos, 2004); por tanto, parece importante analizar la influencia del país de origen como objeto de anticonsumo de una manera más completa. Con el incremento de la preocupación social y medioambiental en la sociedad, es posible esperar que - al menos para un segmento de la población - los factores de tipo social y/o medioambiental sean considerados como importantes antecedentes del anticonsumo dirigido hacia un país. La historia de boicots medioambientales (y sociales) contra países extranjeros (véase Braunsberger y Buckler, 2011) ejemplifica la importancia de explorar factores alternativos a los factores político-económicos - más frecuentemente investigados - , en relación con la imagen de países extranjeros.

Los mecanismos de influencia del país de origen sobre los consumidores operan a distintos niveles: país, producto/marca y atributo (Leonidou, Palihawadana y Talias, 2007; Amine, 2008; Roth y Diamantopoulos, 2009). Por ejemplo, una persona puede tener una imagen negativa sobre un país (en general) y tratar de evitar sus productos pero, sin embargo, y al mismo tiempo, esa misma persona puede tener una percepción positiva sobre la calidad de los productos de una determinada categoría fabricados en ese país y, por tanto, estar dispuesta a la compra de los mismos. Como podemos intuir a raíz del ejemplo anterior, si los distintos niveles de influencia del país de origen convergen en la misma dirección - fomentando la compra o el rechazo, según el caso- los consumidores estarán más dispuestos a actuar en consecuencia - comprando o evitando comprar un determinado producto de un determinado país. Sin embargo, tal y como hemos visto en el ejemplo, niveles distintos de influencia del país de origen pueden provocar la activación de distintos mecanismos en la mente del consumidor, haciendo las decisiones de consumo y anticonsumo más difíciles.

Analizando la literatura sobre el país de origen desde el punto de vista del anticonsumo, es posible que exista rechazo como consecuencia de la imagen que los consumidores tienen del país. Esto quiere decir que, en oposición a la mayor disposición a comprar de los consumidores cuando la imagen que tienen de un determinado país de origen es positiva (Balabanis y Diamantopoulos, 2004), los consumidores evitarán productos de aquellos países sobre los que tienen imágenes negativas. Esta composición de la imagen del país hace posible que en la mente de los consumidores 
existan distintas imágenes para cada pareja 'país-categoría de producto' (Leonidou, et al., 2007).

La mayoría de los trabajos que han utilizado el país de origen como objeto de rechazo al consumo, se han centrado en dos conceptos: el etnocentrismo, que constituye el rechazo a la compra de productos extranjeros sin excepción (Shimp y Sharma, 1987), y la animosidad, la cual implica que los consumidores evitan productos de un determinado país si tienen sentimientos de antipatía o rivalidad hacia este (Klein et al., 1998). Siguiendo esta perspectiva, la guerra y el domino económico (Nijssen y Douglas, 2004) han sido los dos motivos subyacentes a la animosidad más estudiados, a pesar de la literatura que defiende que la animosidad presenta distintos antecedentes para cada pareja de países (Riefler y Diamantopoulos, 2007).

En resumen, este trabajo trata de arrojar luz sobre los antecedentes de las prácticas de anticonsumo y resistencia a consumir teniendo como objeto de rechazo el país de origen. Con el fin de analizar las posibles interacciones categoría de producto-país se tendrá en cuenta tanto el rechazo de los productos procedentes del país de forma general como para una categoría específica de producto. Se espera que, junto a las motivaciones previamente descubiertas y analizadas en la literatura, surjan razones alternativas que junto con las tradicionalmente analizadas fomenten el anticonsumo hacia un país. En concreto, se espera que estas razones alternativas para el anticonsumo estén influidas por aspectos de tipo social y medioambiental.

\section{Metodología}

\subsection{Selección del sector: industria textil}

Varios son los motivos que apoyan la elección de la industria textil a la hora de descubrir razones de evitación relacionadas de forma más específica con el binomio producto-país que trata de investigar este trabajo. En primer lugar, se trata de una categoría de producto con la que se espera que el consumidor medio esté ampliamente familiarizado. Además, las prendas de vestir tienen un gran valor simbólico y se utilizan comúnmente como un medio de comunicación de la identidad propia (Hogg et al., 2009). Por otra parte, se trata de un sector que últimamente está dando que hablar por su modelo de producción: durante los últimos años, las empresas dominantes en este sector se han preocupado principalmente por el incremento de la productividad, el acortamiento de los tiempos de distribución y el incremento de la obsolescencia mediante el cambio frecuente de las tendencias de la moda. Todas estas prácticas tienen en común el objetivo de fomentar una mayor frecuencia de compra por parte de los consumidores. Este sistema productivo es altamente contaminante y las condiciones laborales de los trabajadores están 'diseñadas' para conseguir los costes más bajos posibles. Es en este contexto, un cada vez mayor número de consumidores está preocupándose por las condiciones que rodean el origen y proceso de manufacturación de las prendas de vestir que consumen. 


\subsection{Selección de la muestra}

La recogida de datos tuvo lugar entre el 29 de septiembre y el 15 de octubre de 2011 en las casas o lugares de trabajo de los entrevistados. La literatura existente muestra la idoneidad del consumidor medio ${ }^{1}$ - frente a consumidores pertenecientes a grupos homogéneos minoritarios, como son los activistas, simplificadores voluntarios, o consumidores 'verdes' - a la hora de analizar los fenómenos de evitación y rechazo de consumo (Lee et al., 2009). Dos procedimientos de muestreo complementarios fueron empleados para este caso: conveniencia y 'bola de nieve'. En este sentido, los primeros entrevistados fueron seleccionados por conveniencia y, tras la entrevista, a cada participante se le pidió que recomendara a otra persona que pudiera estar dispuesta a colaborar con la investigación. El único e importante requisito exigido a los entrevistados fue que fuesen personas encargadas de realizar sus propias compras. En cuanto características de sexo y edad, se dio prioridad a mujeres y entrevistados con edades entre 20 y 40 años para garantizar la máxima representación posible de personas con preocupaciones medioambientales ${ }^{2}$. La muestra final consiste en 21 personas con edades comprendidas entre los 22 y los 62 años. Predominan las mujeres (67 por 100 de la muestra) sobre los hombres - en parte, como consecuencia de la mayor implicación de las mujeres en las actividades y tareas de compra - y las personas con un nivel de educación alto (38 por 100 de la muestra declaró tener estudios universitarios). El Cuadro 1 detalla las características sociodemográficas (género, edad y ocupación) de las personas entrevistadas:

\footnotetext{
${ }^{1}$ El consumidor medio se define en la legislación europea como «el consumidor medio, que está normalmente informado y es razonablemente atento y perspicaz, teniendo en cuenta factores sociales, culturales y lingüísticos» (Reglamento 1924/2006).

${ }^{2}$ La literatura ha revelado la mayor preocupación e implicación medioambiental de personas de sexo femenino y personas jóvenes o de mediana edad (DIAMANTOPOULOS et al., 2003).
} 


\section{CUADRO 1}

CARACTERÍSTICAS SOCIODEMOGRÁFICAS DE LOS ENTREVISTADOS

\begin{tabular}{|c|c|c|c|c|}
\hline Entrevistado & Genero & Edad (años) & Nivel estudios & Ocupación \\
\hline A. & Hombre & 32 & Primarios & Trabajador cuenta ajena \\
\hline A.E. & Mujer & 31 & FP & Trabajador cuenta ajena \\
\hline A.P. & Mujer & 25 & Universitarios & Trabajador cuenta ajena \\
\hline A.T. & Mujer & 54 & Universitarios & Trabajador cuenta ajena \\
\hline B. & Mujer & 27 & FP & Trabajador cuenta ajena \\
\hline D. & Hombre & 28 & Universitarios & Trabajador cuenta ajena \\
\hline E. & Mujer & 24 & FP & Trabajador cuenta ajena \\
\hline H. & Hombre & 33 & FP & Trabajador cuenta ajena \\
\hline $\mathrm{I}$. & Hombre & 37 & Universitarios & Trabajador cuenta ajena \\
\hline I.M. & Mujer & 32 & Primarios & Trabajador cuenta ajena \\
\hline J.M. & Hombre & 61 & Universitarios & Trabajador cuenta propia \\
\hline J.P. & Hombre & 58 & Universitarios & Trabajador cuenta ajena \\
\hline L. & Mujer & 22 & Secundarios & Estudiante \\
\hline L.E. & Mujer & 25 & Universitarios & Desempleada \\
\hline L.R. & Mujer & 53 & Primarios & Desempleada \\
\hline M. & Mujer & 27 & Primarios & Trabajador cuenta ajena \\
\hline M.D. & Mujer & 56 & Primarios & Desempleada \\
\hline M.G. & Hombre & 29 & Universitarios & Trabajador cuenta ajena \\
\hline M.J. & Mujer & 30 & Secundarios & Desempleada \\
\hline M.M. & Mujer & 33 & Secundarios & Trabajador cuenta ajena \\
\hline M.N. & Mujer & 62 & Primarios & Desempleada \\
\hline
\end{tabular}

\subsection{Recogida y análisis de datos}

Hasta donde alcanza el conocimiento de los autores, no hay demasiada literatura que analice todo el rango de efectos que puede motivar la evitación de productos de un determinado país. Para estas situaciones, resulta de gran utilidad el empleo de un enfoque cualitativo, puesto que proporcionará los datos necesarios para obtener una visión más completa de los fenómenos de anticonsumo, teniendo como objeto del mismo un país en concreto (Miles y Huberman, 1994).

Teniendo en cuenta la naturaleza exploratoria del trabajo, se consideró adecuado el uso de entrevistas semi-estructuradas como método de recolección de la información. Para este fin, se desarrolló un guión específico que ayudó a dirigir el proceso de entrevistas (véase Apéndice 1). Este método permite a los investigadores obtener información sobre todos los puntos de interés, y proporciona flexibilidad a la hora de permitir a los participantes extenderse y dar más detalles sobre aquellos temas que la 
investigación considere interesantes. De esta manera, se llevaron a cabo entrevistas cara a cara a en los domicilios o lugares de trabajo de los participantes (según su elección). La duración de las mismas fue de aproximadamente 20 minutos; en la primera parte, se pidió a los entrevistados que hablaran de sus sentimientos de animosidad o antipatía hacia otros países; de esta manera, los autores fueron capaces de descubrir la variedad de antecedentes/componentes que subyacen a estos sentimientos.

La segunda parte de la entrevista se centró específicamente en la evitación del consumo de prendas de vestir a nivel de producto/marca, tienda y de país de origen. Como se comentó anteriormente, es probable que existan diferencias entre distintas categorías de producto para el mismo país (Amine, 2008; Roth y Diamantopoulos, 2009).

Cada entrevista fue grabada y posteriormente transcrita para su mejor análisis. Dentro de cada entrevista, se seleccionó la información relevante para la investigación. La información seleccionada fue analizada y separada en segmentos que contuviesen ideas o argumentos diferenciados. A cada una de estas ideas se le asignó un código que resumiera su contenido. Estos códigos fueron posteriormente clasificados en categorías teniendo en cuenta su similitud; estas categorías a su vez también fueron agrupadas de forma sucesiva. De esta forma, fue posible descubrir aquellos aspectos y motivaciones que subyacían a las prácticas de anticonsumo de los entrevistados (Miles y Huberman, 1994).

\section{Resultados}

\subsection{Anticonsumo dirigido al país en general: la importancia del afecto}

Cuando se les preguntó directamente si tenían sentimientos de animosidad hacia otros países, tan sólo unos pocos encuestados fueron capaces de reconocerlos abiertamente. De éstos, China destacó como principal país objeto de animosidad; el motivo más frecuentemente mencionado fue la expansión de negocios y productos procedentes de dicho país en España y las consecuencias que esto supone para la economía nacional. Una idea repetida $-\mathrm{y}$ no sólo por aquellos encuestados que mostraban animosidad hacia China, sino en general por toda la muestra - es la percepción de peligro que supone el creciente poder económico y la expansión de la economía china.

«...se van a llevar todo lo que hay [...] Mi trabajo depende de los chinos... me voy a ir al traste por los chinos.» I. M. (Mujer, 32)

Otros países - aunque menos mencionados - fueron los países árabes en general. En estos casos, los entrevistados se refirieron principalmente a temas culturales.

Sin embargo, a pesar de no reconocer sentimientos de animosidad, la gran mayoría de los entrevistados fueron capaces de nombrar un país hacia el que sintieran antipatía 
cuando se les preguntó por ello. Los resultados obtenidos con esta pregunta apuntan hacia una gran variedad de aspectos que pueden motivar los sentimientos negativos hacia un determinado país - por ejemplo, cultura y aspectos sociales - más allá de los tradicionalmente analizados — aspectos de tipo bélico y/o económicos.

«Pues... por parte de sus creencias, por su visión de la mujer, por temas religiosos...que no estoy de acuerdo con ellos... básicamente.» M. G. (Hombre, 29)

Cuando se les preguntó por su comportamiento hacia productos del país que había sido seleccionado, una diferencia interesante surgió entre aquellos entrevistados que habían declarado tener sentimientos de animosidad hacia un país y los que tan sólo habían manifestado antipatía. En este sentido, mientras que todos aquellos que manifestaron sentir animosidad evitaban los productos procedentes del país objeto de esos sentimientos, para los entrevistados que manifestaron sentir antipatía, la evitación de productos no estaba generalizada, encontrándose casos tanto de evitación como de no evitación y casos en los que tan sólo algunas categorías de producto eran evitadas. Los resultados ponen de manifiesto la importancia de tener en cuenta la categoría del producto a la hora de analizar las posibles influencias del país de origen. Además, muestran la importancia de los sentimientos de los individuos a la hora de llevar a cabo comportamientos de anticonsumo.

«[...] más que nada, más que por la cultura, por lo que su cultura está en relación a lo que hacen... sobre sus actuaciones, ¿no? Centran su religión como método para justificar cualquier acción... y el fin nunca justifica los medios [...] Intento ni fijarme, por lo que he dicho, en tiendas de este tipo (tiendas propiedad de ciudadanos de procedencia árabe).» J. M. (Hombre, 58)

«Porque considero que allí siempre están de conflictos y no debe ser fácil la vida. Tampoco me gusta cómo tratan a las mujeres [...] Sí (compraría productos procedentes de los países árabes) si me gustaran y tuviesen un buen precio.» M. N. (Mujer, 62)

«Bueno, los juguetes sí. Por lo menos, los que se venden en los mercados en ferias y similares. [...] También evito comprar la comida. Me da respeto por todas las cosas que se comentan.» M. J. (Mujer, 31)

\subsection{Anticonsumo específico de una categoría de producto: comportamiento de evitación de compra de ropa}

Como se esperaba, la selección de la categoría de producto - prendas de vestir - demostró ser útil a la hora de descubrir distintas manifestaciones de evitación de consumo en relación con los distintos niveles analizados. Muchos de los participantes sacaron a relucir el tema del país de origen de forma espontánea, tanto a 
nivel de marca como de tienda. En caso contrario, eran preguntados directamente. Teniendo en cuenta los resultados obtenidos en este apartado, es posible ver como, una vez más, China es el país hacia el que van dirigidos más comportamientos de anticonsumo:

«Creo que utilizan muy mal material y, aparte, la esclavitud que tienen allí y la contaminación.» A. E. (Mujer, 31)

Sin duda, la principal razón de evitación de productos procedentes de China dada por los entrevistados fue la baja calidad percibida. Esta característica fue vinculada - como muestra la cita anerior-, con imágenes negativas de país en cuestiones sociales y mediomabientales. Asimismo, la baja calidad fue mencionada frecuentemente junto con otros aspectos relacionados con el producto en sí, tales como diseño poco atractivo, duración inferior a la deseada y en general, malas experiencias personales con prendas de vestir procedentes de este país.

«Las pocas veces que he entrado (en una tienda de propiedad china) no me ha gustado el género ni el estilo. Hay veces que prefiero gastar un poco más y que te guste la ropa y te dure más, antes que eso.» M. G. (Hombre, 29)

«Es que hay ropa china que es de muy mala calidad.» M. M. (Mujer, 33)

«Porque no me gusta la calidad de los productos que venden. No los considero buenos.» A. (Hombre, 32)

Algunos entrevistados mostraron además preocupación por los controles de calidad y garantías que se le exigen a los productos chinos. Las opiniones dadas en este caso mostraron una percepción bastante negativa de los productos textiles provenientes de China, sobre todo en los casos de aquellos entrevistados que mencionaron el país de origen a nivel de tienda. Esto quiere decir que, a pesar de que dos prendas estén fabricadas en China, las que además son vendidas en establecimientos de propiedad china son peor percibidas que las que no lo son.

«Resulta que las calidades de la ropa china no están vigiladas ni tienen los controles sanitarios que deben tener. Entonces China, pues no.» J. M. (Hombre, 61)

Considerando otros motivos distintos de la calidad y seguridad del producto, fue posible detectar algunos aspectos relacionados con la creación y la definición de la imagen personal. Este es un aspecto bastante común en el ámbito de la gestión de la imagen en el sentido en que, para algunas personas, es muy importante crear un estilo propio, por lo que están dispuestos a emplear un mayor esfuerzo en buscar productos que les diferencien y evitar vestir igual que la mayoría de la gente. En este sentido, la evitación de consumo llega a influir a distribuidores españoles que comercializan bajo su marca productos que a veces han sido manufacturados en China. 
«Es cierto que ciertas prendas las hacen en una tirada más grande, como unos pantalones, o una camiseta que yo rechazaría. Quizá no la rechazaría sino que no me gustaría llevarla... que luego te vas cruzando por la calle y ves quinientas como la tuya... que pasa perfectamente en establecimientos como Blanco o Bershka.» M. (Mujer, 27)

Con estas respuestas, parece quedar fuera de toda duda la importancia que las creencias respecto a un producto, en relación con su lugar de origen, tienen como mecanismo que fomenta la evitación de consumo de dicho producto.

Más allá de las consideraciones sobre las características del producto, algunos participantes revelaron preocupaciones morales sobre la compra de productos provenientes de ciertos países de origen. En este sentido, los participantes utilizan el rechazo de prendas de vestir procedentes de China como forma de actuar contra el impacto y la expansión de las actividades chinas en la economía española. Así, una entrevistada declaró evitar productos chinos porque:

«Prefiero comprar productos españoles.» L. R. (Mujer, 53).

Tal y como se esperaba, la preocupación por las condiciones laborales a la que son sometidos los trabajadores del sector textil en China surgió entre los encuestados.

«Sencillamente, porque no me gusta la ropa china. No me gusta porque los precios que ponen y todos sus costes son a expensas de los trabajadores que tienen superexplotados... ipues no quiero!» M. N. (Mujer, 62)

«Generalmente, los productos que vienen de China compiten en precio, pero eso es por la explotación que tienen. El gobierno está de explotador de toda la gente. Lo evito, si puedo lo evito.» J. P. (Hombre, 58)

«No voy a comprar algo de Nike que han hecho en Taiwan, China o la India, cuando se ha hecho a base del poder que tiene con ellos.» L. E. (Mujer, 25)

\subsubsection{Diferencias entre el país de diseño y el país de fabricación}

Se dio el caso de uno de los participantes que, a pesar de tener actitudes negativas hacia las prendas de vestir chinas, confesó que era imposible evitarlas debido a la difusión de estos productos por todo tipo de tiendas (de propiedad china o no).

«(No evito) ninguno. Compras ropa y luego es de China, aunque te la compres en El Corte Inglés.» M. D. (Mujer, 56)

Como consecuencia de esta y otras menciones a la gran difusión que tienen las prendas de vestir de procedencia china en España, se preguntó a los entrevistados 
si para ellos existían diferencias entre ropa manufacturada en China y vendida en España en tiendas de propiedad china y ropa manufacturada en China, pero vendida en España bajo otras marcas o en otro tipo de tiendas. Los resultados mostraron una clara división de opiniones. Entre aquellas personas que declararon percibir diferencias, la principal fue una vez más la calidad. Los participantes perciben que las marcas occidentales cumplen unos estándares de calidad más exigentes que las chinas; esto, a su vez, se traduce en menciones a las diferencias en términos de duración, materiales, diseño y seguridad para la salud.

«Si tú ves o has probado unas zapatillas Adidas o Nike que están producidas en China, tú ves una calidad. Pero la ropa que ellos (los chinos) a menudo venden en tiendas chinas... a mí, cuando he visto el género, no me ha gustado.» M. G. (Hombre, 29)

«Porque las que se producen en China por otras marcas tienen una calidad, tienen unas garantías. Lo que fabrican ellos y traen clandestino no tiene ni marca ni calidad.» L. R. (Mujer, 53)

«La calidad que les puede exigir un fabricante de una empresa $\mathrm{X}$ no es la que quizás ellos... o sea, ellos pueden fabricar cosas buenas y cosas malas. Si tú les exiges que te fabriquen cosas buenas te van a fabricar cosas buenas $y$, si no, pues ellos podrán fabricar lo que estimen. El problema es que lo que venden en el comercio chino es barato, barato y de calidad muy dudosa.» H. (Hombre, 33)

Un aspecto importante que surgió de las respuestas de algunos participantes, es el hecho de que para éstos, los productos de procedencia china vendidos en tiendas que no son de propiedad china o vendidos bajo una marca reconocida, puede hacerles pensar que el producto es mejor, cuando en realidad puede ser que no haya diferencias en términos de calidad o seguridad.

«Estéticamente sí que hay diferencia, parece tener más calidad. Pero luego, en realidad es lo mismo (en el proceso de fabricación), la han hecho en el mismo sitio. O sea, que yo creo que no, no hay diferencia.» L. (Mujer, 22)

«Si no le ves la etiqueta, quizá lo aceptas. Si la compras en tiendas con más categoría, te da más confianza. Y al comprarlas en las tiendas de los chinos, puedes decir: pues no, es peor.» M. D. (Mujer, 56)

Los casos anteriormente mencionados muestran un ligero escepticismo, pero prefieren evitar comprar en tiendas propiedad de ciudadanos chinos en España. Sin embargo, otros encuestados se mostraron totalmente escépticos: algunos hablaron de una «doble moral» (J. P. Hombre, 58) y otros directamente apuntaron a que la única diferencia existente era «el precio.» (B. Mujer, 27) 
«He tenido la experiencia de ir a un chino y que el zapato, por ejemplo, valga $X$ y llegar a una zapatería y que lo vendan como novedad de invierno, como de temporada. Y que sea hasta tal punto de llegar a ser 6 ó 7 euros más caro... y es el mismo.» A. P. (Mujer, 25)

«Que casi toda la ropa de, por ejemplo, Zara... bueno, el grupo Inditex... todo eso se fabrica allí en China, ¿no? Yo creo que sí. [...] Según la imagen que yo tengo, casi toda la ropa que se vende en Europa la hacen en China. La hacen a 1 euro y te la venden a 30 euros Tommy Hilfiger, Lacoste, u otras marcas y, como tontos, pues la compramos.» D. (Hombre, 28)

\subsection{La importancia de los aspectos morales (sociales y medioambientales)}

Los resultados hasta ahora comentados muestran como algunos participantes directamente apuntaron consideraciones morales como motivo para evitar el consumo de prendas de vestir de un determinado país (China principalmente, aunque en menor medida también se mencionan otros países asiáticos). Parece claro que, para estos consumidores, las condiciones del país en el que se fabrican las prendas de vestir son importantes a la hora de tomar la decisión de compra. Sin embargo, y puesto que uno de los principales objetivos del trabajo es comprender el papel que juegan estos aspectos morales en las decisiones de anticonsumo con respecto al país de origen, a aquellos entrevistados que no los mencionaron previamente, se les preguntó de forma explícita si tenían en cuenta los aspectos sociales y medioambientales del país de origen a la hora de comprar prendas de vestir.

Las preocupaciones medioambientales del país de origen surgieron como motivos relevantes del anticonsumo, únicamente al preguntar por la categoría de producto de prendas de vestir. Las manifestaciones vinculadas con la imagen medioambiental negativa del país de origen fueron los juicios de mala calidad de los productos y el rechazo generalizado el consumo.

«Sí, yo pienso en eso (en las cuestiones medioambientales). Por eso he dicho que utilizan malos materiales a la hora de fabricar los productos.» A. E. (Mujer, 31).

«Sí que lo tengo mucho en cuenta. Si no, no compro nada.» L. E. (Mujer, 25).

Pese a las respuestas mayoritariamente negativas sobre la importancia de los aspectos medioambientales para el anticonsumo de productos extranjeros, los autores consideran que la variedad de argumentos o excusas dadas para no tener en cuenta estos datos proporcionan una información que merece la pena analizar cuidadosamente.

Una excusa bastante común - que además ha sido considerada en la literatura como una importante barrera para la adquisición de ropa responsable con el medio 
ambiente (Connell, 2010) - es la falta de información o conocimiento suficiente. En este sentido, mientras algunos entrevistados se quejan de que no existe información sobre las prácticas sociales o medioambientales del país de origen, otros reclaman la necesidad de recibir información que esté contrastada. En general, estos participantes son bastante escépticos con respecto a la información proporcionada sobre las condiciones en las que las prendas de vestir son producidas.

«Porque yo creo que es mentira (la existencia de problemas sociales y medioambientales asociados al consumo de ropa). No estoy informada de eso.» M. D. (Mujer, 56)

«(Hablando de motivos de rechazo) La manera en que se produce. Si los que la hacen sufren mucho... por ejemplo, los niños (explotados en las fábricas). Lo que pasa es que, al no estar informados, pues tampoco lo sé. Pero si lo supiera quizá no la compraría.» E. (Mujer, 24)

«Yo prefiero que las personas no estén explotadas, ni que intenten hacer estas prendas económicas gracias a eso, a los trabajadores. Y en temas medioambientales, a la hora de comprar, claro, si yo sé que es una fábrica que tiene muchos vertidos y no tiene en cuenta temas de medio ambiente, la verdad es que no me gustaría nada comprar sus productos, pero tampoco tenemos las nociones de esa situación.» L. (Mujer, 22)

«Lo que pasa es que muchas veces la información que llega tienes que contrastarla. No porque una noticia diga que las zapatillas Nike son de China y explotan a los niños... yo necesito otro organismo más independiente que una noticia en Internet para no comprarlo. Entonces no me creo tampoco todo lo que digan, a menos que sea de muchas fuentes, sea contrastado. En el caso de que sí, sí me negaría a comprarlo.» M. G. (Hombre, 29)

Sin embargo, para otros participantes, el problema no es la falta de información, sino la irrelevancia de la misma en la decisión de (no) compra. A pesar de manifestar estar al tanto de los posibles problemas medioambientales y sociales que la compra de productos textiles acarrea, esta información no es considerada en el momento de llevar a cabo la compra; esto puede ser debido a la influencia de otros factores situacionales más directamente relacionados con la adquisición de este tipo de productos.

«No, porque en ese momento no lo pienso. Es como cuando sale en las noticias el tema de los vaqueros que utilizaban para desgastarlos un tipo de producto que producía la enfermedad del pulmón y eso ni me lo podría haber imaginado. Y sinceramente, yo veo un vaquero y en el momento de comprármelo no estoy pensando en eso. Es que ni me acuerdo, sinceramente. A lo mejor si en el momento me dices: no, esto produce esto, puede ser que me suscite un poco de rechazo, pero si no, ni se me pasa por la cabeza.» M. (Mujer, 27)

«Cuando voy a comprar la ropa no lo tengo en cuenta. Luego cuando lo veo por la tele sí, pero cuando voy a comprar la ropa no.» B. (Mujer, 27) 
«De hecho, Nike tiene (la fábrica) en Tailandia... y tienen contratados a niños... y aun así yo sigo comprando esa marca. No pienso, no me acuerdo cuando voy a comprar quién ha fabricado realmente esa prenda o esa zapatilla.» I. (Hombre, 37)

Otra excusa dada apunta a la percepción de que a nadie le importan los problemas sociales y medioambientales a la hora de adquirir productos textiles. En este aspecto, la literatura ha mostrado la importancia de las normas sociales y la presión del grupo en los comportamientos de adquisición y rechazo de compra en el caso de las prendas de vestir (Hogg et al., 2004).

«No (tengo en cuenta aspectos sociales y medioambientales a la hora de comprar ropa). Pero yo creo que nadie (los tiene).» A. P. (Mujer, 25)

Un entrevistado destaca la mayor importancia relativa de los aspectos o preocupaciones socicales, frente a la imagen medioambiental del país de origen, en referencia a la categoría de producto de prendas de vestir:

«No pienso en ello. Yo creo que la ropa no se relaciona con elementos medioambientales normalmente. De hecho, creo que la ropa con lo que más se relaciona es con la explotación infantil. Que en esos temas sí estamos más concienciados. Pero a nivel medioambiental no, no le veo ninguna relación. Puedo ver si hay alguna noticia, pero no le prestas atención, no lo relacionas. Relacionas más temas como la explotación infantil o explotación laboral en tema de ropa. Pero medioambiental... temas medioambientales, muy muy poquito.» M. G. (Hombre, 29)

Los entrevistados también hablaron sobre la gran complejidad de tener en cuenta este tipo de preocupaciones a la hora de tomar decisiones relacionadas con la (no) compra. Como consecuencia de la dificultad de realizar el comportamiento adecuado, el sentimiento de no tener alternativa surge entre los participantes:

«Cuando yo voy a comprar no me planteo si detrás de eso hay gente viviendo en malas condiciones, trabajando las 24 horas del día... porque entonces no comerías, porque si comes te acuerdas de la gente de África que no come nada... ¡Y es que entonces no vivirías!» A. T. (Mujer, 54)

«(Los problemas sociales y medioambientales) No influyen. Porque la misma ropa que hay en las tiendas españolas se ha hecho igual.» D. (Hombre, 28)

Además, para algunos encuestados, las consideraciones morales no son importantes a la hora de llevar a cabo el comportamiento de compra, puesto que consideran los problemas relacionados con estos temas como algo lejano y que no les afecta. 
«Porque no pienso en general en los problemas que hay en China.» M. J. (Mujer, 30)

Finalmente, valores como el egoísmo, preferencias del consumidor por 'lo práctico' y valoración de productos de bajo precio fueron resaltados como razones o excusas para no considerar la imagen social o medioambiental del país de origen, a la hora de comprar prendas de vestir:

«No (tengo en cuenta temas sociales o medioambientales). Mal hecho, porque no pienso en eso en ese momento... soy egoísta.» E. (Mujer, 24).

«Yo soy una persona práctica. Prefiero ese dinero invertirlo en cosas para diario, aunque sean de menor calidad. Un quita y pon: cuando está muy estropeada, la tiras y te compras otra.» A. T. (Mujer, 54).

\section{Conclusiones}

El presente trabajo constituye una prueba más de la utilidad de los efectos del país de origen a la hora de explicar las decisiones de compra de los consumidores referido a una industria particular, tanto a nivel general como para algunas categorías de producto. Teniendo en cuenta el efecto del país de origen, en general es posible afirmar que, pese a no tratarse de un fenómeno generalizado, existe el sentimiento de animosidad hacia otros países. En el presente trabajo, el objetivo de animosidad más frecuentemente mencionado fue China. Respecto a los motivos, éstos estuvieron en línea con la literatura existente sobre animosidad, al apuntar hacia la influencia negativa que las actividades chinas tenían en la economía, sobre todo en la española. También se corroboró la relación positiva entre la existencia de sentimientos de animosidad y la evitación de productos procedentes del país objetivo del mismo (Klein et al., 1998; Nijssen y Douglas, 2004). Estos resultados ponen de manifiesto la importancia de la animosidad hacia otro país, en comparación con otros mecanismos producidos por el país de origen que puedan coexistir a la hora de fomentar el rechazo de productos en general.

Sin embargo, la mayoría de los entrevistados no mostró sentimientos tan intensos sino que declararon sentir antipatía. Para aquellos que declararon sentir antipatía hacia algún país, la evitación de productos no se dio en todos los casos: existían también personas dispuestas a consumir productos de aquel país que 'les caía mal' o que trataban de evitar sólo algunas categorías de producto. Los países árabes fueron los más citados en este apartado. Las razones que subyacen a estos sentimientos negativos comprendieron las tradicionalmente estudiadas razones de tipo bélico y económico (i.e., Klein et al., 1998), pero los participantes también mencionaron motivos políticos, culturales, religiosos y sociales, menos investigados (Roth y Diamantopoulos, 2009). Contrariamente a lo esperado, las motivaciones de tipo medioambiental no surgieron como razón para sentir animosidad por un determinado país. 
Teniendo en cuenta el nivel de categoría de producto, las entrevistas muestran una vez más a China como país de origen a evitar, sobre todo si además de fabricado el producto es vendido en tiendas de propiedad china en España. Para este comportamiento de anticonsumo, los participantes ofrecieron distintas explicaciones. La opinión mayoritaria es que los productos textiles procedentes de china son de mala calidad, tienen un diseño poco atractivo y pasan menos controles de seguridad. En cambio, algunos participantes eligen evitar la compra de prendas de vestir procedentes de China no por el producto en sí, sino por las condiciones en las que éste es fabricado, es decir, la explotación a la que, según su criterio, se ven sometidos los trabajadores de las fábricas Chinas.

A pesar de estos pocos individuos mostrando preocupación, para la mayor parte de la muestra los aspectos sociales y/o medioambientales de la compra de ropa no representan un problema a tener en cuenta durante el proceso de compra. Esto podría ser una consecuencia de la composición de la muestra (consumidores medios, en vez de activistas o simplificadores voluntarios). Cuando específicamente se les pregunta por estos problemas, la mayoría menciona excusas y barreras que ciertamente no son nuevas en la literatura sobre consumo sostenible de prendas de vestir (Connell, 2010); las excusas o barreras citadas, en el ámbito medioambiental, por los consumidores entrevistados en el presente estudio incluyen: irrelevancia o falta de consideración de las cuestiones medioambientales del país de origen en el momento de compra; mayor valoración de productos de bajo precio; valores egoístas; falta de conocimiento suficiente sobre las condiciones o prácticas medioambientales del país de origen, o escepticismo con la información sobre esas cuestiones; o la desconexión de los condicionantes medioambientales del país de producción con la categoría de producto específica de prendas de vestir. Entre las anteriores barreras/excusas, cabe resaltar la importancia que los participantes dan al papel de la información o conocimiento sobre los aspectos sociales y medioambientales del país de origen. Los resultados hacen pensar que una mejor información (i.e., información más creíble) sobre la situación del sector podría traducirse en una mayor incidencia de las consideraciones sociales y medioambientales en los procesos de toma de decisiones de anticonsumo. En este sentido, parece adecuado destacar que, precisamente los pocos entrevistados que se han mostrado influidos por estas cuestiones, únicamente han resaltado una situación de explotación de los trabajadores; tema que ha sido tratado ampliamente desde hace años en distintos tipos de medios de comunicación. Por el contrario, el alto grado de impacto ambiental provocado por la industria textil está recibiendo atención desde hace relativamente menos tiempo. Este desconocimiento por parte del 'gran público' podría explicar la ausencia de consideraciones sobre la contaminación producida por el sector textil en determinados países como motivo de anticonsumo.

La prevalencia de China como país de origen a evitar, puede ser debida a la proliferación de tiendas propiedad de ciudadanos chinos en todo el territorio nacional y la gran difusión que los productos 'Made in China' tienen en el mercado español. Es bastante probable que los consumidores españoles tengan imágenes y actitudes 
parecidas sobre otros productores asiáticos de prendas de vestir, pero la primera opción que acude a la mente de los consumidores al pensar en producto textil debe ser China, como consecuencia de su mayor importancia a nivel global y mayor atención recibida por parte de los medios de comunicación.

Destacamos algunas implicaciones de los resultados obtenidos para la gestión empresarial y de marketing, en particular. Si bien parece poco probable que las empresas puedan o deban difundir mensajes que fomenten los sentimientos negativos hacia otros países, sí que es posible aprovechar esos sentimientos o animosidad mediante el fomento de la 'conveniencia o deber' de comprar productos nacionales. Otra implicación importante del trabajo realizado se deriva de la mayor importancia relativa de la imagen político-económica y social del país de origen - frente a la imagen medioambiental (actualmente) - para explicar el fenómeno de anticonsumo de productos extranjeros. En este sentido, las empresas españolas pueden enfatizar valores como el buen trato a los trabajadores, la seguridad y la puesta en marcha de programas de mejora del entorno social con el fin de que las prácticas de otros países sean percibidas como peores y, por tanto, sus productos sean evitados y se desarrolle preferencia por los productos nacionales. De nuestro trabajo también se desprenden implicaciones para productores que deslocalizan su producción a terceros países en particular, China o Bangladesh. Para estas empresas puede ser interesante enfatizar su vinculación con el país de origen de la empresa y desvincularla del país de producción. Finalmente, las administraciones públicas pueden ayudar a mejorar la percepción en terceros países de la calidad de los productos de una industria (como la textil), mediante el fomento de prácticas de tipo medioambiental, control y aumento de la presión regulatoria.

\section{Limitaciones y futura investigación}

El presente trabajo revela la existencia de anticonsumo de productos de una industria motivado por razones ligadas a la dupla industria/país de origen. Además, en él se realiza una aportación a la literatura previa al ser uno de los primeros en explorar la existencia de anticonsumo derivado de cuestiones sociales y medioambientales en entrevistas en profundidad realizadas a 21 sujetos. Sin embargo, debe de tenerse en cuenta la existencia de limitaciones intrínsecas al diseño cualitativo y exploratorio de esta investigación. La principal limitación de este estudio, al igual que ocurre con otros trabajos de naturaleza cualitativa y exploratoria, es la imposibilidad de generalizar los resultados obtenidos; ni en términos de población ni para otras categorías de producto. En este sentido, aspectos relativos al procedimiento de muestreo (conveniencia y 'bola de nieve') o características de la muestra pueden haber condicionado los resultados obtenidos - aunque no es probable que haya incidido en la importancia de los aspectos medioambientales del país de origen en las decisiones de compra de los 'consumidores medios' entrevistados. 
Así pues, parece necesario que en el futuro esta investigación sea extendida con el apoyo de métodos cuantitativos. En las entrevistas realizadas, los sujetos mostraban preocupaciones de carácter social, ligadas la explotación de los trabajadores, como argumento para no comprar productos textiles chinos. Sin embargo, aunque los entrevistados entendían que dichas preocupaciones pudiesen extenderse a cuestiones medioambientales en dicha industria y país, afirmaron que no constituyan un factor relevante en sus procesos de compra. El tamaño muestral y la naturaleza cualitativa no permiten sacar conclusiones sobre si esta ausencia de efecto puede extenderse al conjunto de la población. Un estudio cuantitativo arrojaría luz sobre esta cuestión e incluso podría identificar el tamaño del nicho de mercado que puede manifestar anticonsumo a raíz de cuestiones medioambientales y sociales, hecho que sería de gran interés para académicos, administraciones públicas y directivos.

Otro aspecto importante a tener en cuenta es que el presente trabajo ofrece una visión estática del fenómeno de anticonsumo en España en relación con el país de origen. Por tanto, es importante considerar que, con el paso del tiempo, los sentimientos y creencias registrados aquí tenderán a evolucionar y fluctuar (Amine, 2008), haciendo de esta manera interesante el desarrollo de estudios longitudinales, a diferentes niveles, sobre el anticonsumo basado en preocupaciones medioambientales.

Por último, sería interesante analizar diferencias en la relevancia y efectos de imágenes de país de carácter medioambiental en los fenómenos anticonsumo, basados en el país de origen, entre muestras conformadas por 'consumidores medios' y segmentos más específicos de consumidores/ciudadanos caracterizados por un mayor compromiso de protección medioambiental, como son los activistas ambientales, simplificadores voluntarios, o consumidores 'verdes'.

\section{Referencias bibliográficas}

[1] AMINE, L. S. (2008): «Country of origin, animosity and consumer response: Marketing implications of antiAmericanism and Francophobia», International Business Review, . $^{\circ} 17$, junio, pp. 402-422.

[2] BALABANIS, G. y DIAMANTOPOULOS, A. (2004), «Domestic country bias, country-of-origin effects, and consumer ethnocentrism: A multidimensional unfolding approach», Journal of the Academy of Marketing Science, n. . 32, enero, pp. 80-95.

[3] BLACK, I. R. y CHERRIER, H. (2010): «Anticonsumption as part of living a sustainable lifestyle: Daily practices, contextual motivations and subjective values», Journal of Consumer Behavior, $\mathrm{n} .^{\circ}$ 9, diciembre, pp. 437-453.

[4] BRAUNSBERGER, K. y BUCKLER, B. (2011): «What motivates consumers to participate in boycotts: Lessons from the ongoing Canadian seafood boycott», Journal of Business Research, n. ${ }^{\circ}$ 64, enero, pp. 96-102.

[5] CHATZIDAKIS, A. y LEE, M. S. W. (2013): «AntiConsumption as the Study of Reasons Against», Journal of Macromarketing, n. ${ }^{\circ}$ 33, septiembre, pp. 190-203, 
[6] CHERRIER, H. (2009): «Anticonsumption discourses and consumer-resistant identities», Journal of Business Research, n. ${ }^{\circ}$ 62, febrero, pp.181-190.

[7] CHERRIER, H.; BLACK, I. R. y LEE, M. (2011): «Intentional non-consumption for sustainability? Consumer resistance and/or anticonsumption?», European Journal of Marketing, n. ${ }^{\circ}$ 45, noviembre/diciembre, pp. 1757- 1767.

[8] CONNELL, K. Y. H. (2010): «Internal and external barriers to eco-conscious apparel acquisition», International Journal of Consumer Studies, n. ${ }^{\circ}$ 34, marzo, pp. 279-286.

[9] DIAMANTOPOULOS, A.; SCHLEGELMILCH, B. B.; SINKOVICS, R. R. y BOHLEN, G. M. (2003): «Can socio-demographics still play a role in profiling green consumers? A review of the evidence and an empirical investigation», Journal of Business Research, n. ${ }^{\circ}$ 56, junio, pp. 465-480.

[10] HOGG, M. K.; BANISTER, E. N. y STEPHENSON, C. A. (2009): «Mapping symbolic (anti)consumption», Journal of Business Research, n. ${ }^{\circ}$ 62, febrero, pp. 148-159.

[11] HUNEKE, M.E. (2005): «The face of the unconsumer: an empirical examination of the practice of voluntary simplicity in the United States», Psychology \& Marketing, n. ${ }^{\circ} 22$, julio, pp. 527-550.

[12] IYER, R. y MUNCY, J. A. (2009): «Purpose and object of anticonsumption», Journal of Business Research, n. ${ }^{\circ}$ 62, febrero, pp. 160-168.

[13] JENNINGS, P. D. y ZANDBERGEN, P. A. (1995): «Ecologically sustainable organizations: An institutional approach», Academy of Management Review, n. ${ }^{\circ}$ 20, agosto, pp. 1015-1052.

[14] KLEIN, J. G.; ETTENSON, R. y MORRIS, M. D. (1998): «The animosity model of foreign product purchase: an empirical test in the People's Republic of China», The Journal of Marketing, n. ${ }^{\circ}$ 62, enero, pp. 89-100.

[15] LEE, M. S. W.; MOTION, J. y CONROY, D. (2009): «Anticonsumption and brand avoidance», Journal of Business Research, n. ${ }^{\circ}$ 62, febrero, pp. 169-180.

[16] LEONIDAS, L. C.; PALIHAWADANA, D. y TALIAS, M. A., (2007): «British Consumers' Evaluations of US Versus Chinese Goods», European Journal of Marketing, n. ${ }^{\circ} 41$, julio/agosgo, pp. 786-820.

[17] MILES, M. y HUBERMAN, M. (1984): Qualitative data analysis: A source book of new Methods, Beverly Hills: Sage.

[18] MOISANDER, J. (2007): «Motivational complexity of green consumerism», International Journal of Consumer Studies, n. ${ }^{\circ}$ 31, julio, pp. 404-409.

[19] NIJSSEN, E. J. y DOUGLAS, S. P. (2004): «Examining the animosity model in a country with a high level of foreign trade», International Journal of Research in Marketing, n. ${ }^{\circ} 21$, enero, pp. 23-38.

[20] PIACENTINI, M. G. y BANNISTER, E. N. (2009): «Managing anticonsumption in an excessive drinking culture», Journal of Business Research, $\mathrm{n}^{\circ}$ 62, febrero, pp. 279288.

[21] RIEFLER, P. y DIAMANTOPOULOS, A. (2007): «Consumer animosity: A literature review and a reconsideration of its measurement», International Marketing Review, n. ${ }^{\circ} 24$, enero, pp. 87-119.

[22] ROTH, K. P. y DIAMANTOPOULOS, A. (2009): «Advancing the country image concept», Journal of Business Research, n. ${ }^{\circ}$ 62, julio, pp. 726-740.

[23] SHIMP, T. A. y SHARMA, S. (1987): «Consumer ethnocentrism: construction and validation of the CETSCALE», Journal of Marketing Research, pp. 280-289. 
[24] THOMPSON, C. J. y ARSEL, Z. (2004). «The Starbucks brandscape and consumers' (anticorporate) experiences of glocalization», Journal of Consumer Research, n. ${ }^{\circ} 31$, junio, pp. 631-642.

[25] VAREY, R. J. (2010): «Marketing means and ends for a sustainable society: A welfare agenda for transformative change», Journal of Macromarketing, n. ${ }^{\circ} 30$, febrero, pp. $112-126$. 